\title{
Method of Handling Nuclear Waste in Nuclear Power Engineering
}

\author{
Tatyana A. Kulagina* and Vladislav A. Popkov ${ }^{a, b}$ \\ a Siberian Federal University \\ 79 Svobodny, Krasnoyarsk, 660041, Russia \\ ${ }^{b}$ Radiochemical plant Mining and Chemical Combine \\ 53 Lenin st., Zheleznogorsk, 662970, Russia
}

Received 12.01.2015, received in revised form 04.02.2015, accepted 01.03.2015

In the article presents the results of investigations of the processes solidify liquid of radioactive waste low and intermediate level to inorganic astringent (cementation process). Formed by cementing the product has a number of advantages: high mechanical strength, is not combustible, radiation and chemically stable, low external radiation cementations materials due to the high density. Cementing of technology as conditioning of liquid radioactive waste is a process of immobilization of liquid radioactive waste to cement matrix to obtain a solid final product (cement compound). Substantiated the use of of effects cavitational technology, quite easy to implement, energy efficient and in some cases having no alternative. Disposal of waste radiochemical production during the decommissioning of nuclear power plants on the basis of impulse cavitational technology increases the strength the cement compound.

Keywords: cement compound, cavitational technology, the decommissioning of nuclear power plants.

\section{Метод обращения с отходами ядерного топлива в атомной энергетике}

\author{
T.А. Кулагина ${ }^{a}$, В.А. Попков ${ }^{a, 0}$ \\ ${ }^{a}$ Сибирский федеральньий университет \\ Россия, 660041, Красноярск, Свободный, 79 \\ ${ }^{6}$ Радиохимический завод Горно-химического комбината \\ Россия, 662970, Железногорск, Ленина, 53
}

Изложены результаты исследований процессов отверждения жидких радиоактивных отходов низкого и среднего уровней активности в неорганические вяжущче (процесс иементирования). Образуюшийся при иементировании продукт обладает иельм рядом достоинств: имеет высокую механическую прочность, является негорючим, радиационно

(C) Siberian Federal University. All rights reserved

* Corresponding author E-mail address: tak.sfu@gmail.com 
и химически устойчив, понижено внешнее излучение цементных материалов из-за высокой плотности. Цементирование как технология кондииионирования жидких радиоактивных отходов представляет собой процесс иммобилизаиии жидких радиоактивных отходов в цементную матрииу с получением твёрдого конечного продукта (иементного компаунда). Показана иелесообразность использования эффектов кавитационной технологии, достаточно легко реализуемой, энергоэффективной и в ряде случаев не имеющей альтернативы. Утилизаиия отходов радиохимического производства при выводе из эксплуатации ядерных энергетических установок на базе кавитаџионной технологии приводит к повымению прочности иеементного компаунда.

Ключевые слова: ичементный компаунд, кавитационная технология, вывод из эксплуатации ядерных энергетических установок.

\section{Введение}

Развитие ядерной энергетики, создание ядерного оружия, широкое внедрение ядернофизических методов во все области науки и техники привели к образованию совершенно нового типа техногенных отходов - радиоактивных, которые из-за содержания в них радионуклидов нельзя безопасно ни уничтожить, ни захоронить. Хотя количество радиоактивных отходов по сравнению с другими техногенными отходами ничтожно мало (приблизительно 0,5 \% от всех промышленных отходов), их специфика требует разработки особых технологий обращения с ними и применения специальных методов обеспечения безопасности для человека и биосферы [1].

К особому виду отходов относятся отходы ядерного топлива (ОЯТ). Они содержат большое количество радионуклидов (в том числе особо опасных), обладающих весьма разнообразными ядерно-физическими, радиационными и физико-химическими свойствами. Проблемой является то, что для каждого из них необходимо найти такой способ обращения, который гарантировал бы его безопасность для внешней среды на протяжении всего времени его существования.

Из-за высокой радиоактивности отходов обращение с ними должно быть дистанционным, в хорошо защищенных конструкциях. До недавних пор отходы требовали их утилизации таким образом, чтобы они не представляли опасности для человека в течение 10000 лет. Во временно́й перспективе радионуклиды в резервуарах опасны для окружающей среды и здоровья человека в период от 300 до 200000 лет и более.

Существуют несколько форм и слоев отходов, которые неоднородны во всех фазах, как внутри отдельного резервуара, так и среди различных резервуаров. Обычно отходы имеют три основные формы:

жидкость состоит из воды, растворенных солей и других химических соединений и располагается над плотными слоями или между ними, иногда погружаясь в солевой осадок;

солевой осадок - кристаллизованные солевые отходы, образующиеся поверх ила, в основном растворимые в воде;

ил (nульпа) - плотный нерастворимый в воде компонент, который осаждается на дне резервуара, образуя толстый слой переменной консистенции (рис. 1).

В настоящее время на предприятиях ядерно-энергетического цикла во всём мире возникли проблемы по переработке высокоактивных отходов, накопленных за последние полвека.

$$
-199-
$$




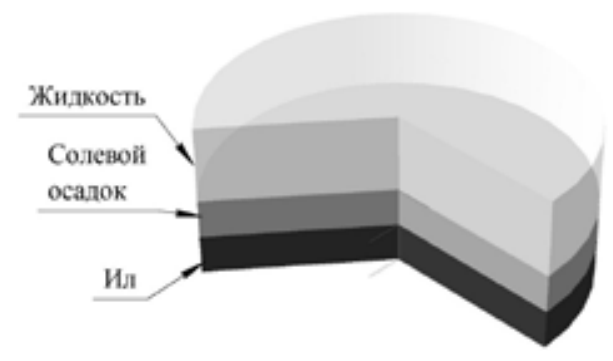

Рис. 1. Форма накопленных отходов

Практика показала, что длительное хранение активных жидких отходов приводит к накоплению твердого осадка - пульпы. Именно эта форма отходов и является наиболее сложной с точки зрения переработки и утилизации.

Как в России, так и в США, имеющих наибольшее количество подобных отходов (около 80 \% от мировых запасов), пульпы формировались в течение длительного времени при отстаивании взвесей, содержащихся в различных по составу жидких радиоактивных отходах. В процессе эксплуатации емкостей для хранения ОЯТ осветленные растворы декантировали, осадок уплотнялся и за счет накопления в твердой фазе тепловыделяющих радионуклидов температура повышалась (в отдельных слоях до $130{ }^{\circ} \mathrm{C}$ ). В настоящее время пульпы имеют достаточно высокий уровень радиоактивности и неоднородный состав. Механизмы образования твердых труднорастворимых осадков и их состав достаточно полно описаны в работах [2-4].

В соответствии с Международной конвенцией о безопасности обращения с радиоактивными отходами на всех его этапах должны быть обеспечены эффективные средства защиты отдельных лиц, общества в целом и окружающей среды от вредного воздействия радионуклидов и ионизирующего излучения как в настоящее время, так и в будущем. С точки зрения долговременной безопасности наиболее важным этапом обращения с радиоактивными отходами является их длительное хранение и захоронение.

Одним из факторов, обеспечивающих безопасность длительного хранения и захоронения радиоактивных отходов, служит их физико-химическая характеристика. При выборе формы отходов, подлежащих захоронению, следует учитывать не только соответствие ее качества действующим нормативным требованиям, но и экономические факторы.

Наиболее широко используемым в настоящее время процессом отверждения жидких радиоактивных отходов низкого и среднего уровней активности является включение жидких радиоактивных отходов (ЖРО) в неорганические вяжущие (процесс цементирования). Образующийся при цементировании продукт обладает целым рядом достоинств: высокой механической прочностью, негорючестью, радиационной и химической устойчивостью, пониженным внешним излучением цементных материалов из-за высокой плотности.

Цементирование как технология кондиционирования жидких радиоактивных отходов представляет собой процесс иммобилизации ЖРО в цементную матрицу с получением твёрдого конечного продукта (цементного компаунда), направляемого далее на безопасное длительное хранение [5, 6]. Процесс цементирования заключается в смешении жидких солевых концентратов и пульп с цементом с последующим схватыванием и образованием твердого монолита. 
В настоящее время для хранения цементного компаунда используют два типа контейнеров: невозвратный защитный контейнер НЗК-150-1,5 [7] и стандартная 200-литровая металлическая бочка [8]. И в том и в другом случае возможен сильный разогрев цементного компаунда в процессе его твердения.

В этой связи целесообразно использование принципиально иных наукоемких технологий, в частности эффектов кавитационной технологии, достаточно легко реализуемой, энергоэффективной и в ряде случаев не имеющей альтернативы [9-11]. Утилизация отходов радиохимического производства при выводе из эксплуатации ядерных энергетических установок на базе кавитационной технологии уже достаточно хорошо себя зарекомендовала [12-14].

\section{Направление исследований}

Для разработки нового наукоемкого метода обращения с радиоактивными отходами в лаборатории ФГУП «Горно-химический комбинат» произведена серия экспериментальных работ по созданию цементных компаундов. Определялась зависимость свойств цементного компаунда от режима приготовления цементной смеси, подготовки пульпы и свойств используемой воды, которая приготавливалась с применением эффектов гидродинамической кавитации.

Основными задачами при выполнении работ являются:

- проверка влияния физико-химических свойств воды на качество получаемого цементного компаунда;

- проверка влияния ультразвукового воздействия на пульпу перед «включением» ее в цементный компаунд.

Результаты исследования лягут в основу предложенного метода подготовки радиоактивных отходов (РАО) к отверждению в виде цементного компаунда, а также их составляющих.

\section{Контрольно-измерительные приборы и оборудование}

Для измерения концентрации растворённого кислорода и температуры использован анализатор растворённого кислорода «МАРК-201», предназначенный для питьевых, поверхностных и сточных вод. Для измерения содержания растворенного в воде кислорода в данном анализаторе используется амперометрический датчик по принципу полярографической ячейки Кларка закрытого типа.

Для измерения $\mathrm{pH}$, окислительно-восстановительного потенциала, электропроводности и температуры воды был использован 4-параметрический портативный измерительный прибор Water Test фирмы Hanna Instruments (Германия). Прибор измеряет значения:

- pН в диапазоне от 0 до 14;

- окислительно-восстановительный потенциал от 1000 до + 1000 мВ;

- электропроводность - от 0 до $2000 \cdot 10^{-6} \mathrm{OM}^{-1} \cdot \mathrm{cm}^{-1}$;

- температуру от 0 до $60{ }^{\circ} \mathrm{C}$.

Основная погрешность измерений в указанных поддиапазонах составляет $\pm 0,05$ единицы $\mathrm{pH}$.

Измерение кислородосодержания воды проводилось с помощью кислородного датчика № 5972, работающего по принципу гальванического датчика (элемента), сила тока в котором пропорциональна парциальному давлению растворенного в жидкости кислорода. Кислородо-

$$
-201-
$$


Таблица 1. Физико-химические показатели воды после кавитационной обработки с различными объёмами заполнения СК-реактора

\begin{tabular}{|l|c|c|c|c|c|c|c|c|c|c|}
\hline \multirow{2}{*}{$V, \%$} & \multicolumn{2}{|c|}{$T,{ }^{\circ} \mathrm{C}$} & \multicolumn{2}{c|}{ КРК, \% нас } & \multicolumn{2}{c|}{$x, \mathrm{OM}^{-1} / \mathrm{cm}$} & \multicolumn{2}{c|}{$\mathrm{pH}$} & \multicolumn{2}{c|}{$E, \mathrm{mB}$} \\
\cline { 2 - 11 } & $\alpha=10^{\circ}$ & $\alpha=20^{\circ}$ & $\alpha=10^{\circ}$ & $\alpha=20^{\circ}$ & $\alpha=10^{\circ}$ & $\alpha=20^{\circ}$ & $\alpha=10^{\circ}$ & $\alpha=20^{\circ}$ & $\alpha=10^{\circ}$ & $\alpha=20^{\circ}$ \\
\hline До обработки & \multicolumn{2}{|c|}{20,7} & \multicolumn{2}{|c|}{101,2} & \multicolumn{3}{c|}{0} & \multicolumn{2}{|c|}{5,4} & \multicolumn{2}{c|}{200} \\
\hline 100 & 40,5 & 32,6 & 85,1 & 96,65 & 14,5 & 6 & 5,65 & 5,45 & 133 & 168,5 \\
\hline 65 & 34,6 & 27,2 & 87,65 & 95,7 & 5,5 & 13 & 6,0 & 5,7 & 128,5 & 147 \\
\hline
\end{tabular}

мер обеспечивает непосредственный отсчет процентного насыщения кислородом исследуемого образца воды. Кроме того, был использован прибор Water test фирмы HANNA instrument (Германия). Пределы измерений концентрации кислорода 0-200 \% (100 \% - равновесная концентрация кислорода), точность измерения в пределах автоматической компенсации температуры $\left(0-40^{\circ} \mathrm{C}\right) \pm 3 \%$.

Наличие в воде перекиси водорода $\mathrm{H}_{2} \mathrm{O}_{2}$ определялось по хемилюминесцентной методике: с помощью фотоумножителя ФЭУ-117А измерялась интенсивность хемилюминесцентного свечения смеси исследуемого образца воды и раствора люминола $\mathrm{C}_{7} \mathrm{~N}_{3} \mathrm{O}_{2} \mathrm{H}_{7}$ (хемилюминесценция возникает вследствие реакции взаимодействия люминола с перекисью водорода).

В качестве наладочных испытаний было исследовано влияние заполнения рабочей камеры на изменения физико-химических свойств воды: температура (T), кислородосодержание (КРК), $\mathrm{pH}$, электропроводность $(x)$, окислительно-восстановительный потенциал $(E)$. Для исключения влияния примесей в воде на её активацию в качестве обрабатываемого объекта использовалась дистиллированная вода. Опыты проводились с двумя насадками с углами раскрытия клина $\alpha 10,20^{\circ}$ и объёмами заполнения реактора $V 100$ и $65 \%$. Максимальное число оборотов ротора при использовании насадок с $\alpha 10^{\circ}$ и $V 100 \%$ составляло 9000 об/мин, с $\alpha=20^{\circ}$ и $V 100 \%-$ $n 6500$ об/мин. В случае с $V 65 \%$ число оборотов ротора при использовании каждой насадки соответствовало предыдущему случаю. Продолжительность каждой обработки составляла 330 с. Каждый опыт проводили трижды, из трёх полученных значений выбирали два наиболее близких по величине и вычисляли их среднее значение. Результаты эксперимента приведены в табл. 1.

\section{Вспомогательное оборудование}

Мешалка магнитная ММ-5 предназначена в качестве вспомогательного оборудования при измерении концентрации растворенного в воде кислорода. Технические характеристики прибора:

- регулирование скорости вращения плавное, в пределах от 400 до 1200 об/мин;

- максимальное количество перемешиваемого раствора 1,5 л;

- предельная кинематическая вязкость перемешиваемых растворов не более $5 \cdot 10^{-6} \mathrm{M}^{2} / \mathrm{c}$;

- конструкция мешалки обеспечивает возможность подогрева перемешиваемых растворов до температуры $(40 \pm 5){ }^{\circ} \mathrm{C}$. 


\section{Изменение физико-химических свойств воды}

Известно, что после гидродинамической обработки воды ее физико-химические характеристики существенно изменяются, что позволяет использовать модифицированную воду в технологических процессах водоподготовки и коррекции свойств воды в энергетических комплексах $[10,11,15]$. В данной работе проведена серия опытов по определению влияния кавитационного воздействия на физико-химические свойства воды при условии максимального кавитационного эффекта.

В опытах применялся суперкавитационный реактор с крыльчаткой с различными углами раскрытия клина $\alpha: 10,20,30,40,60,70,80,90^{\circ}$ [16]. Для опытов с дистиллированной водой использовали дистиллят водопроводной воды, который хранился в закрытом сосуде в затемнённом месте в течение трёх суток после перегонки. Для опытов с отстоявшейся водопроводной водой брали воду из водопроводной сети, промытой в течение 30 мин, затем отстаивали в неплотно закрытом сосуде в затемнённом месте в течение тридцати суток. В опытах с водопроводной водой анализируемая вода бралась из городской водопроводной сети. Предварительно водопровод промывали в течение 30 мин и оставляли открытым на протяжении периодического отбора проб. Разовая проба водопроводной воды подлежала обработке только один раз.

В [17] приведено описание опытов по изменению кислородосодержания при обработке воды в СК-реакторе. Обработка воды проводилась при постоянной частоте вращения ротора $n$, равной 8 тыс. об/мин при разной длительности: 10, 30, 60, 120, 240 с. Полученные результаты свидетельствуют о наибольшем изменении кислородосодержания при максимальном времени обработки.

Исходя из полученных результатов обработка проводилась с постоянной длительностью 330 с при разных числах $n: 1600,5000$ и 10000 об/мин. Показания температуры $T$, кислородосодержания КРК, $\mathrm{pH}$, электропроводности $x$, окислительно-восстановительного потенциала $E$ снимались измерительными приборами непосредственно до и после обработки. Каждый опыт выполняли по три раза. Из трех полученных результатов выбирали два наиболее близких по значению и вычисляли их среднюю величину.

Далее экспериментальные результаты обрабатывали в программе Microsoft Excel. В связи с тем что эксперименты проводили в разное время, значения физико-химических показателей воды до обработки разнятся. Таким образом, обработанные результаты представлены в виде

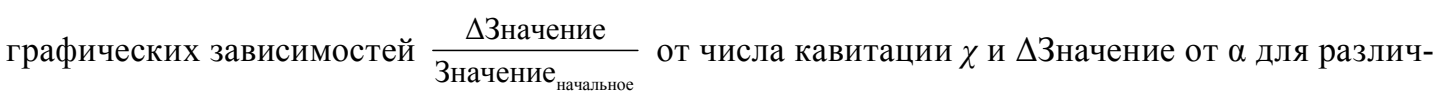
ных $n$. Число кавитации - безразмерная величина, определяемая отношением

$$
\chi=\frac{P_{a}-P_{d}}{\rho \frac{V^{2}}{2}},
$$

$P_{a}$ - атмосферное давление; $P_{d}$ - давление насыщения пара для данной температуры воды; $\rho-$ плотность; $V$ - скорость потока.

$$
-203-
$$


Так как температура воды в процессе обработки повышалась, то давление насыщения пара для данной температуры воды брали для средней температуры $T_{\mathrm{cp}}$ :

$$
T_{\mathrm{cp}}=T_{\mathrm{H}}+\frac{T_{\mathrm{K}}-T_{\mathrm{H}}}{2}
$$

где $T_{\text {н }}$ - температура до обработки; $T_{\text {к }}$ - температура после обработки.

\section{Определение времени релаксации модифицированных физико-химических свойств воды}

Обработку воды проводили в гидродинамическом суперкавитационном реакторе. Исходя из экспериментальных данных исследования проводили с крыльчатками с углами раскрытия клина $(\alpha)$ :

- дистиллированная вода: 20, 40, 70, 90;

- отстоявшаяся водопроводная вода: $20,30,80,90^{\circ}$;

- водопроводная вода: $80,90^{\circ}$.

Частота вращения ротора (n) составляла 10 тыс. об/мин. Исследуемые пробы воды помещали в стерилизованную химическую посуду с клапанным поршнем, служащим для предотвращения доступа атмосферного воздуха, при комнатной температуре. Первые показания снимали через 1 ч, затем через 24 ч и т. д. (табл. 2).

В процессе кавитационной обработки воды происходит увеличение температуры и электропроводности. Максимальное увеличение электропроводности дистиллированной воды, соответствующее значению $28,3 \cdot 10^{-6} \mathrm{OM}^{-1} \mathrm{~cm}^{-1}$, схоже с увеличением электропроводности при термической активации с нагревом до $200{ }^{\circ} \mathrm{C}$ и связано с диссоциацией молекул воды на катионы водорода и анионы гидроксила. Наиболее значительное увеличение электропроводности отстоявшейся водопроводной воды связано как с диссоциацией молекул воды, так и с ионизацией примесей. Уменьшение концентрации растворенного кислорода происходит вследствие действия как теплового (из-за снижения растворимости кислорода в воде с ростом температуры), так и химического факторов, что выражается в повышении $\mathrm{pH}$.

Установлено, что зависимости изменения физико-химических свойств от режима обработки имеют подобный характер для всех типов воды, а степень изменения пропорциональна увеличению частоты вращения ротора, следовательно, уменьшению числа кавитации. Время кавитационной обработки также существенно влияет на физико-химические параметры воды. Максимальное влияние кавитационного воздействия наблюдается при минимальных числах кавитации до значения $\chi 0,02$ и продолжительности воздействия около $300 \mathrm{c}$.

Таблица 2. Время проведения измерений физико-химических показателей воды после обработки

\begin{tabular}{|l|l|}
\hline \multicolumn{1}{|c|}{ Вода } & \multicolumn{1}{|c|}{ Время проведения измерений $t_{\text {рел. }}$ ч } \\
\hline Дистиллированная & $1,24,48,72,96,216,312,552,1584$ \\
\hline Отстоявшаяся водопроводная & $1,24,48,72,120,168,384,624,1656$ \\
\hline Водопроводная & $1,24,48,72,120,168,336,567,1608$ \\
\hline
\end{tabular}




\section{Методика экспериментальных исследований}

Результаты экспериментальных исследований по использованию кавитационноактивированной воды для извлечения пульпы из хранилищ объектов ядерной техники приведены в работах [1, 12-14].

Солесодержание здесь определяли на кондуктометре «Эксперт-002», рН - на приборе иономер универсальный ЭВ-74. Фторопластовые формы с цементной смесью помещали на 24 ч в камеру нормального твердения при температуре $20 \pm 3{ }^{\circ} \mathrm{C}$ и относительной влажности воздуха $(95 \pm 5) \%$. Через сутки образцы извлекали из форм и помещали обратно в камеру нормального твердения на 28 сут. После выдержки образцы испытывали на прочность. Для обеспечения сопоставимости результатов механическую прочность определяли по двум образцам.

Механические испытания на сжатие (ГОСТ 310.4) проводили на гидравлическом прессе ВM-3,4 (диапазон производимого усилия 5500 кН, напряжение питания $220 \mathrm{~B}$, мощность 1,0 кВт). Для определения морозостойкости использовали шкаф холодильный типа «Ларь» ШН(L)Y-0,175 «Бирюса-200К-5» (температура полезного объема - не выше минус $180{ }^{\circ} \mathrm{C}$, напряжение питания - $220 \mathrm{~B}$, мощность - 150 Вт).

В работе применены отраслевые инструкции:

1. ОИ 001.725-2011 Цементные компаунды на основе радиоактивных отходов. Определение предела прочности на сжатие на испытательной машине марки TESTING.

2. ОИ 001.729-2011 Цементные компаунды. Определение устойчивости к длительному пребыванию в воде. Методика проведения испытаний.

3. ОИ 001.730-2011 Цементные компаунды. Определение морозостойкости. Методика проведения испытаний.

\section{Экспериментальное исследование и результаты}

Для определения состава аликвоту пульпы высушили до постоянной массы, затем высушенную твёрдую фазу $\left(0,1455\right.$ г) сплавили с метаборатом лития $\left(\mathrm{LiBO}_{2}\right)$. Сплав охладили и растворили в 63 г/л растворе азотной кислоты (100 мл). Полученные растворы анализировали фотометрическим, атомно-абсорбционным и радиометрическими методами в соответствии с инструкциями по анализу технологических растворов, утвержденными на ГХК. По результатам анализов рассчитывали состав пульпы (на грамм высушенной). Результаты анализа осадка приведены в табл. 3.

Согласно требованиям федеральных норм и правил НП-019-2000 «Сбор, переработка, хранение и кондиционирование жидких радиоактивных отходов. Требования безопасности» указаны допустимые значения по удельной альфа-активности цементного компаунда: $<3,7 \cdot 107$ Бк/кг. В табл. 4 приведены характеристики промышленной и подготовленной воды. Результаты механических испытаний представлены в табл. 5.

\section{Вывод}

На основании полученных результатов можно отметить, что применение кавитационной технологии существенным образом сказалось на упрочнении цементного компаунда, что хорошо согласуется с результатами, полученными ранее для гидротехнических бетонов.

$$
-205-
$$


Таблица 3. Химический и радионуклидный состав пробы пульпы

\begin{tabular}{|c|c|c|c|}
\hline \multirow{2}{*}{$\begin{array}{c}\text { Компонент или } \\
\text { показатель }\end{array}$} & \multirow{2}{*}{ Размерность } & \multicolumn{2}{|c|}{ Величина компонента или показателя } \\
\hline & & 2014 г. & 2010 г. \\
\hline Плутоний & мГ/г (Бк/Г) & $0,199\left(5,17 \cdot 10^{5}\right)$ & 0,362 \\
\hline Уран & $\mathrm{M} \Gamma / \Gamma$ & $<6,9$ & 184 \\
\hline МЭД & мкР/Г'c & $6,9^{-3}$ & $3,4^{-2}$ \\
\hline$\beta$-активность & $\mathrm{Ku} / \Gamma$ & $4,1 \cdot 10^{-2}$ & $6,4 \cdot 10^{-2}$ \\
\hline $\begin{array}{l}\text { Гамма-активность, } \\
\text { в том числе }\end{array}$ & Бк/Г & $\Sigma 6,88 \cdot 10^{6}$ & \\
\hline Цезий-137 & Бк/Г & $6,6 \cdot 10^{6}$ & \\
\hline Цезий-134 & Бк/Г & $3,4 \cdot 10^{3}$ & \\
\hline Европий-155 & Бк/Г & $1,6 \cdot 10^{5}$ & \\
\hline Европий-154 & Бк/Г & $1,1 \cdot 10^{5}$ & \\
\hline Кобальт-60 & Бк/Г & $5,7 \cdot 10^{3}$ & \\
\hline
\end{tabular}

Таблица 4. Характеристики используемой воды для затворения

\begin{tabular}{|l|c|c|}
\hline \multirow{2}{*}{\multicolumn{1}{|c|}{ Образец воды }} & \multicolumn{2}{|c|}{ Значение показателя } \\
\cline { 2 - 3 } & $\mathrm{pH}$ & солесодержание, мг/л \\
\hline Вода из ППВ & 7,5 & 310 \\
\hline Образец № 1 & 7,8 & 3,01 \\
\hline Образец № 2 & 7,7 & 2,64 \\
\hline Образец № 4 & 7,6 & 0,65 \\
\hline
\end{tabular}

Таблица 5. Исходная механическая прочность цементных компаундов

\begin{tabular}{|c|c|c|c|c|c|c|c|c|c|}
\hline \multicolumn{2}{|c|}{ Показатель } & \multicolumn{8}{|c|}{ Механическая прочность компаунда через 28 сут, МПа } \\
\hline В/Ц & $\mathrm{B} / \mathrm{B}$ & \multicolumn{2}{|c|}{ С пром. водой } & \multicolumn{2}{|c|}{ С водой обр. № 1} & \multicolumn{2}{|c|}{ С водой обр. № 2} & \multicolumn{2}{|c|}{ С водой обр. № 4} \\
\hline \multirow{2}{*}{0.5} & \multirow{2}{*}{0.41} & 36,0 & 32,5 & 27,4 & 27,7 & 39,2 & 45,2 & 52,2 & 43,0 \\
\hline & & \multicolumn{2}{|c|}{ Средн. 34,2} & \multicolumn{2}{|c|}{ Средн. 27,5 } & \multicolumn{2}{|c|}{ Средн. 42,2} & \multicolumn{2}{|c|}{ Средн. 47,6} \\
\hline
\end{tabular}

Растекаемость 190 мм. 


\section{Список литературы}

[1] Кулагина Т.А., Кулагин В.А., Матюшенко А.И. Техносферная безопасность в ядерной энергетике: Учебное пособие. Красноярск, 2014. 286 с.

[2] Ермолаев В.М. и др. // Радиохимия. 2006. Т. 47. № 3. С. 374-379.

[3] Шилов В.П., Федосеев А.М. // Радиохимия. 2003. Т. 45. № 5. С. 441-444.

[4] Тананаев И.Г., Мясоедов Б.Ф. Химическое поведение плутония в щелочных отходах: формы существования, редокс-реакции и структурные превращения. М.: Институт геохимии и аналитической химии РАН им. В.И. Вернадского, 2002. 356 с.

[5] Шведов В.П., Седов В.М., Рыбальченко И.Л., Власов И.Н. Ядерная технология. М.: Атомиздат, 1979. $536 \mathrm{c}$.

[6] ГОСТ Р 51883-2002. Отходы радиоактивные цементированные. Общие технические требования.

[7] ГОСТ Р 51824-2001. Контейнеры защитные невозвратные для радиоактивных отходов из конструкционных материалов на основе бетона.

[8] ГОСТ 30765-2001 Тара транспортная металлическая. Общие технические условия.

[9] Kulagin V.A., Kulagina L.V., Kulagina T.A. // Journal of Siberian Federal University. Engineering \& Technologies. 2008. (1). Issue 1. 76-85.

[10] Ивченко В.М., Кулагин В.А., Немчин А.Ф. Кавитационная технология: монография / ред. акад. Г.В. Логвинович. Красноярск: Изд-во КГУ, 1990. 200 с.

[11] Демиденко Н.Д., Кулагин В.А., Шокин Ю.И. Моделирование и вычислительные технологии распределенных систем: монография / ред. чл.-корр. РАН А.М. Федотов. Новосибирск: Наука, 2012. 424 c.

[12] Козин О.А., Кулагина Т.А. // Гидродинамика больших скоростей и численное моделирование: материалы III Междунар. летней науч. шк. Кемерово: ИНТ, 2006. С. 141-144.

[13] Кулагина Т.А., Матюшенко А.И., Комонов С.В., Писарева Е.Н. Управление промышленными и особоопасными отходами: монография / ред. Б.Ф. Турутин. М.: Изд-во «Маджента», 2010. $567 \mathrm{c}$.

[14] Кулагина Т.А., Козин О.А. // Химическое и нефтегазовое машиностроение. 2010. № 10. C. $12-15$.

[15] Дубровская О.Г., Евстигнеев В.В., Кулагин В.А. // Безопасность жизнедеятельности. 2012. № 3. С. 26-30.

[16] Кулагин В.А., Вильченко А.П. Кулагина Т.А. Моделирование двухфазных суперкавитационных потоков: монография / ред. В.И. Быков. Красноярск: ИПЦ КГТУ, 2001. 187 с.

[17] Кулагин В.А., Кашкина Л.В., Стебелева О.П., Сапожникова Е.С. // ХХІ век: фундаментальная наука и технологии: Материалы международной научно-практической конференции. M., 2012. C. 121-126. 